


\title{
Juan Gelman: la dislocación del lenguaje como vía de denuncia poética
}

\section{Juan Gelman: the dislocation of language as a way of poetic denouncement}

\author{
Eva Castañeda Barrera' \\ Universidad Nacional Autónoma de México \\ evacbarrera@hotmail.com
}

Las heridas no están aún cerradas, su único tratamiento es la verdad y luego la justicia; solo asi es posible el olvido verdadero.

JuAN GELMan

\begin{abstract}
Resumen: La poesía latinoamericana de la segunda mitad del siglo $\mathrm{xx}$ se desarrolló en un contexto cuya complejidad está dada por múltiples procesos sociales y políticos, uno de los más emblemáticos es las dictaduras militares del cono sur. En este escenario, una nómina importante de escritores acudió a nuevas estrategias para dar cuenta de la violencia ejercida por el régimen. Para efectos de este trabajo, analizaremos algunos de los recursos formales que sigue el discurso poético de Juan Gelman para representar y criticar la violencia producto de la dictadura argentina. Palabras clave: poesía, dictadura argentina, Juan Gelman, violencia, denuncia.
\end{abstract}

${ }^{1}$ Becaria del Programa de Becas Posdoctorales de la Universidad Nacional Autónoma de México. Centro de Investigaciones sobre América Latina y el Caribe. Asesorada por el Dr. Carlos Huamán López. 
Abstract: The Latin American poetry of the second half of the 2oth century was developed in a context whose complexity is given by multiple social and political processes, one of the most emblematic is the military dictatorships of the southern cone. In this scenario, a significant list of writers turned to new strategies to account for the violence exerted by the regime. For the purposes of this work, we will analyze some of the formal resources that Juan Gelman's poetic discourse follows to represent and criticize the violence resulting from the Argentine dictatorship.

Keywords: Poetry, Argentine dictatorship, Juan Gelman, Violence, Denunciation.

Recibido: 30 de marzo de 2020

Aceptado: I9 de mayo de 2020 https://dx.doi.org/ I0.15 I74/rv.vi3i28.542

U

Tna parte de la poesía escrita a lo largo de la historia ha mostrado preocupación por causas sociales y políticas específicas. "Esta vertiente lírica, cuyo énfasis está puesto en lo temático, es lo que denominamos poesía política. [...] Se ha escrito desde siempre en Occidente, partiendo de la Grecia clásica" (Aguilera, 2010: 46). $\mathrm{Su}$ devenir se inscribe en una larga trayectoria que da cuenta del momento histórico en el que se produce; el común denominador será el interés por incidir en la realidad mediante la obra artística. En lo que respecta a la tradición de la poesía política en América Latina podemos remontarnos a "Oda a Roosevelt" (1904) de Rubén Darío, hasta llegar a algunos de los autores más representativos de la década de 1960 en adelante; por ejemplo: Nicanor Parra, Roberto Fernández Retamar, Roque Dalton, Paco Urondo y Juan Gelman, por mencionar algunos. Lo cierto es que el desarrollo de la poesía política a lo largo de la historia no ha seguido una trayectoria lineal, y sus formas de representar la realidad se han 
modificado según las condiciones y el contexto histórico. De este modo, no resulta equiparable hablar de la poesía política escrita durante los años sesenta a aquella que se produjo, por ejemplo, en 1980.

En este sentido, ubicamos dos momentos que simbolizan un cruce histórico para el marco temporal que aquí nos ocupa. En principio, la Revolución cubana (1953-1959) -el símbolo más representativo de una vuelta de tuerca en la historia de América Latina para buena parte de los escritores latinoamericanos en la década de 1960- significó un cambio en el modo de concebir el ejercicio literario. Haciendo alusión a tal acontecimiento, Carmen Alemany Bay señala:

La Revolución se convirtió en un factor esperanzador para todos los pueblos de América Latina, y así se observa en muchos poemas de Sabines, Adoum, Benedetti, Gelman, Cisneros, etc. Pero además este evento sirvió de aglutinador personal de muchos de estos poetas. Con el saludo unánime a la Revolución intercambiaron sus experiencias poéticas, y quizá en esos momentos se dieron cuenta de que entre ellos, salvando las distintas realizaciones poéticas de cada autor, tenían un proyecto en común, no solo social sino también literario (Alemany, 1997: 20).

Los poetas que escriben en este contexto encuentran que el compromiso es total, por lo que la obra artística es vista como un medio para incidir en la realidad, ya que "la literatura por la literatura, no sirve para nada. La literatura debe prestar un servicio. [...] Por lo mismo, la poesía debe también ser política. Aunque no propaganda política, sino poesía política” (Cardenal, 1974: VII). Entonces, esta dicción debe ser analizada no solo desde el espectro de lo discursivo, ya que una lectura más integral debe considerar el compromiso que el poeta asume con la realidad circundante, pues 
su praxis política se extiende a todos los ámbitos de la vida. $\mathrm{Mu}$ chos de los autores "se forjan en un ambiente hostil para sus convicciones ideológicas como para su manera de entender la creación literaria. Por esa razón su militancia política estará muy ligada a su aglutinamiento en grupos de muy variada índole cuyo objetivo principal es servir como centros de resistencia” (Aguilera, 2010: 59). En consecuencia, el texto literario funge como un espacio de "combate" en un contexto social que exige una clara toma de partido, "su compromiso directo con la realidad, la asunción de tal compromiso como actitud ética, la necesidad de comunicación y la búsqueda de salvaguardar lo específicamente poético” (61), son algunas de las características que definen a una escritura que se asumió como un vehículo de comunicación y expresión de la solidaridad humana. El papel de esta poesía frente a tal escenario resulta fundamental, dado que, a través de la escritura, el poeta posee una voz autorizada que revisita la historia y la reescribe.

Así pues, la poesía latinoamericana de la segunda mitad del siglo xx se desarrolla en un contexto cuya complejidad está dada por múltiples procesos sociales y políticos. Dos de los más significativos, como ya se advirtió, son la Revolución cubana (1956-1959), y las dictaduras militares que se instauraron en un buen número de países sudamericanos. Muchas de las obras poéticas escritas durante y después de estos conflictos en el cono sur en Latinoamérica (1970-1990) acudieron a la representación ficcional de la violencia para poner en palabras una experiencia aparentemente indecible. Artistas e intelectuales de la época hicieron de sus obras un espacio de crítica frente a la violencia imperante, lo que trajo como consecuencia la proliferación de textos cuya preocupación cardinal era incorporar el tema social como elemento estructural. Los escritores asumieron un compromiso político y estético con la convicción de que el acto poético es también político, por lo que su obra tiene una incidencia en la transformación de la sociedad. La mayoría 
de los escritores exploraron en la fragmentación del lenguaje, uso de neologismos, narratividad exacerbada, mezcla de géneros literarios, entre otras estrategias literarias, para abordar temas políticos y sociales. Por otra parte, acudieron también a las memorias del pasado reciente ${ }^{2}$ para dejar constancia y denunciar desde la literatura lo acontecido durante este periodo signado por la escalada de violencia que se prolongó durante varios años en el cono sur.

La estética como ética será entonces una noción que atraviesa buena parte de la lírica que se escribe durante la década de 1960. Por tal razón, la poesía política será una dicción necesaria en un momento que exige del artista una toma de partido clara. Encontramos un ejemplo de lo anterior en la obra de Juan Gelman (1930-2014), uno de los poetas más importantes del siglo xx y lo que va del Xxi en Latinoamérica; su producción literaria abarca temas diversos, aunque la constante será la reflexión en torno a la derrota política, la narrativa de violencia que ha signado a Latinoamérica, los abusos cometidos por la dictadura militar argentina (1976-1983) y las historias de crimen que se hacen extensivas a otros países del cono sur. La obra poética gelmaniana ocupa su derecho a la denuncia a través de un lenguaje que el mismo autor fue transgrediendo a lo largo de las décadas, pues la sintaxis tradicional no alcanzó para nombrar el horror al que buena parte de la población civil fue sometida durante la dictadura cívico militar. Julio Cortázar, en el prólogo a la Poesía reunida de Gelman, dice:

${ }^{2}$ Las memorias del pasado reciente suelen ser plurales y diversas, son además los relatos que los discursos oficiales, herméticos y ensayados, intentan acallar. Tratan sobre los dramas íntimos y las luchas privadas; cuestiones como la ausencia de familiares o amigos que ya no están, la incertidumbre sobre un paradero que se desconoce, la incomprensión sobre un cuerpo con heridas y cicatrices que distan de ser lo que eran antes o de un hogar que ha tenido que ser abandonado para preservar la integridad propia. Es en este contexto es que las memorias sobre pasados inmediatos se dan. 
Solo leyendo abierto, dejando que el sentido entre por otras puertas que las de la armazón sintáctica o las manoseadas imágenes, metáforas o figuras más o menos arduas pero ya asimiladas a la tradición poética, solo así se accederá a la realidad del poema, que es exacta y literalmente la realidad del horror, la muerte y también la esperanza en la Argentina de nuestros días. A todos nos sucederá lo mismo, la sorpresa ante las continuas transgresiones que se suceden a lo largo del camino, pero solo quienes las asuman y, de alguna manera, las continúen merecerán un libro que quisiera contenerlos, contenernos a todos (2012: 4).

Desde su primer libro, Violin y otras cuestiones (1956), el poeta argentino abordó temas de índole social, aunque también -y de manera un tanto reservada- ya se vislumbra una aportación relevante para renovar los canones de la poesía latinoamericana, de ahí su abordaje a temas cotidianos desde una sintaxis quebrada que echa mano de sustantivos convertidos en verbos, neologismos y diminutivos, por mencionar apenas unos cuántos recursos formales. Su producción posterior como El juego en que andamos (1959) o Gotán (1962) mostraban un cuestionamiento y revisitación de la tradición literaria latinoamericana. En este sentido, es importante señalar que el contexto sociocultural de la década de 1960, momento de publicación de Gotán, resulta fundacional para la poesía en América Latina, pues en distintos países una nómina importante de escritores como Roberto Fernández Retamar, Mario Benedetti, Nicanor Parra, Ernesto Cardenal, entre otros, experimentaban con un lenguaje que se alejaban del discurso grandilocuente y apostaban por una escritura cuyo registro fuera más cercano al habla cotidiana. Carmen Alemany Bay dice al respecto:

En la década de 1960 surge en América Latina una pléyade importante de poetas, cuyo principal propósito fue incorporar el 
lenguaje de la vida a la poesía. Roberto Fernández Retamar acuñó el término de poesía coloquial de tono conversacional, afirmando que esta planteaba un "nuevo realismo" . Es decir, los poetas que se adscribieron a la coloquialidad, buscaron acercarse al lector, aludirlo y no eludirlo como señaló Mario Benedetti. La implicación del lector en el poema y la búsqueda de "un nuevo realismo", debían cubrir una serie de características para lograr tal empresa. [...] Los poetas coloquiales nos describen situaciones reales, acercándose con claridad a la voz que transmite la experiencia inmediata; se arraigan en el quehacer cotidiano y problemático. Apostaron por una poesía que diera cuenta del momento histórico que vivían, en principio, reflexionaron sobre el papel del poeta, ya no como un ser inspirado, sino como un hombre común que le habla a la colectividad (1997: 12).

En este escenario Juan Gelman publica su quinto libro, Cólera buey, parteaguas de un estilo que desplegará en su obra por venir; encontramos en él dos aspectos relevantes de su ciclo poético. Por una parte, el juego verbal -sintaxis que rompe los esquemas del lirismo-, además del exacerbado uso del lenguaje coloquial; por otra parte, una actitud política que se presenta de manera atípica en comparación del discurso poético de la década de los sesenta. Para ejemplificar lo anterior citamos un fragmento de "Aide-Mémoire" para su análisis.

detrás de trajes de mi padre del dedo al pie o en volantes clandestinos que dicen «Viva el pueblo explotado» o era un hermoso gesto de mujer para que le tocaran el pelo inclinó su cabeza como una gran confianza como una entrega en su deseo 
o sea en todas partes me esperan sus poemas

oscuras relaciones con mi historia

bellos desconocidos para mi goce y miedo

entro a ellos sin nombres para que me los digan

me dan manos y pies pero nunca mi rostro sino rostros

jamás el mar sino su oleaje

nunca el otońo en cambio algo como sus oros moviéndose en un patio (Gelman, 2012: 132).

En este texto, la recreación de una situación comunicativa, aunque existe, no es del todo evidente debido a que no hay un mensaje claramente codificado para un interlocutor reconocible, no obstante, la presencia de formas gramaticales que indican su existencia. El poema discurre en dos espacios, uno que corresponde al ámbito de lo privado, representado por su padre y por una mujer. El otro se sitúa en lo público, la guerra en contra de la explotación del pueblo y la lucha por conseguir su liberación. El registro del poema es eminentemente coloquial, pero el contexto comunicativo - a diferencia de los poemas coloquiales tradicionales- no resulta asequible para cualquier lector y esto obedece a que la sintaxis atípica fragmenta la linealidad de la historia: "como una entrega en su deseo / o sea en todas partes me esperan sus poemas / oscuras relaciones con mi historia”. No obstante, el lector puede darle unidad y sentido al texto.

Toda frase lleva consigo una situación comunicativa inmanente y que por el simple hecho de oír o leer una frase reconstruimos en nuestra mente las circunstancias o el contexto en que puede haber sido dicha o escrita, y que le dan sentido. Lo que ocurre con la frase literaria, frente a la comunicativa, es que carece por completo de contexto, y la labor del lector consiste en desarrollar imaginativamente tal contexto (Atienza, 2005: 34). 
En la obra de Juan Gelman, sobre todo la escrita a partir de la década de 1970, el complejizar la forma se traduce en una problematización de su praxis política; recordemos que militó en el Partido Comunista Argentino y en la organización guerrillera Montoneros. En virtud de lo anterior, es importante señalar que lo político y social serán los dos temas más importantes y por ello recurrentes en toda su obra. Dichos tópicos no son nombrados de un modo directo o descriptivo, su militancia y su descontento frente a los hechos sociopolíticos en Argentina lo llevan a atomizar el lenguaje y la sintaxis tradicional para pronunciarse de una manera particular y absolutamente crítica respecto al contexto sociopolítico de su país: "detrás de trajes de mi padre / del dedo al pie o en volantes clandestinos / que dicen "Viva el pueblo explotado»". A este respecto, valdría "preguntarse por los nuevos modos en que la realidad latinoamericana de la década de los setenta se manifiesta en la poesía, y si es que los poetas asumen algún tipo de compromiso frente a esa realidad" (Aguilera, 2012: 69). En el caso específico de Gelman es evidente que asumió una posición política frente a la realidad y al quehacer poético, de modo tal que sus dos libros posteriores, Traducciones III. Los poemas de Sydney West (1969) y Fábulas (1971) estarán atravesados también por esas preocupaciones.

Llegada la década de los setenta, la poesía política ${ }^{3}$ modificará sus formas de representación de la realidad y también su concepción de la violencia. La historia será otra, pues el faro que había

\footnotetext{
${ }^{3}$ Al hablar de "poesía política", estamos decantándonos por una categoría conceptual que refleja de una forma más precisa el objeto de nuestro estudio, habida cuenta que los diversos nombres que este tipo de poesía ha recibido ("realista", "objetiva”, "de protesta”, "militante", "proletaria", "para las masas", "revolucionaria") se refieren a variantes formales de expresión a lo que en última instancia consideramos central para el poema político: el compromiso palmario con una causa que, en su inicio, es extrapoética, pero cuyo tratamiento sirve de partida
} 
representado la Revolución cubana se desdibujará paulatinamente. Los ideales de democracia y justicia que animaron a los distintos países latinoamericanos se verán disminuidos a partir del "Caso Padilla", ${ }^{4}$ en tanto que las dictaduras militares se fortalecerán a partir del golpe de estado de Pinochet en Chile, la dictadura cívicomilitar en Argentina y la instauración de La Operación Cóndor. ${ }^{5}$ La voluntad de cambio que motivó los años sesenta se transformará en desesperanza frente a una violencia sistemática y sostenida por parte de los estados dictatoriales. Este será el escenario sociopolítico del próximo libro de Juan Gelman, Relaciones (1973), en donde explora temas que van desde el paisaje y lo doméstico hasta aquellos que encarnan una crítica social y política, aspecto que, como se ha venido señalando, atravesará con absoluta vehemencia toda su obra.

para la elaboración estética de lo que se convertirá en poema, obra de arte (Aguilera, 2010: 46).

${ }^{4}$ El caso Padilla hace referencia al conflicto que marcó la separación entre la intelectualidad occidental y el régimen castrista. Tuvo su origen en la publicación, en 1968, del poemario Fuera de juego del poeta Heberto Castillo. Dicho libro mereció en un primer momento el principal galardón literario cubano, concedido por la Unión de Escritores y Artistas cubanos, pero las críticas a la revolución castrista, acabaron provocando el encarcelamiento, en 971, del autor. Padilla fue obligado a retractarse y a renegar de sus críticas al gobierno comunista en una declaración pública dirigida a la Unión de Escritores y Artistas Cubanos (Padilla, 1982: 32).

${ }^{5} \mathrm{La}$ operación Cóndor fue un plan de inteligencia diseñado y coordinado por los servicios de seguridad de las dictaduras militares de Brasil, Argentina, Chile, Bolivia, Paraguay y Uruguay, en colaboración con la CIA, para aniquilar a la izquierda opositora durante la década de los setenta. El plan permitió la colaboración de los dictadores Augusto Pinochet (Chile), Hugo Bónzer (Bolivia), Alfredo Stroessner (Paraguay), Joao Figueredo (Brasil), Jorge Rafael Videla (Presidente de la Junta Militar en Argentina) y Juan María Bodaberry (Uruguay) (Ferreira, 2014: 1-27). 
Llegada la década de los setenta una buena parte de los escritores ya no aspiran a transformar la realidad que los circunda, hay por su parte, una renuncia a nombrar verdades históricas totalizantes o completas. Esto en oposición al discurso revolucionario de los años sesenta que privilegió la confianza en el cambio que traería la revolución cubana para todos los países de América Latina. Los escritores que publican durante las década de los setentas y ochentas heredarán un sistema político fallido que encuentra su máxima representación en las dictaduras militares. Por lo tanto, las obras literarias producto de este complejo entramado social dan testimonio del hecho histórico. El poema "Confianzas" ejemplifica lo anterior:

se sienta a la mesa y escribe «con este poema no tomarás el poder» dice «con estos versos no harás la Revolución» dice «ni con miles de versos harás la Revolución» dice y más: esos versos no han de servirle para que peones maestros hacheros vivan mejor coman mejor o él mismo coma viva mejor ni para enamorar a una le servirán no ganará plata con ellos no entrará al cine gratis con ellos no le darán ropa por ellos no conseguirá tabaco o vino por ellos ni papagayos ni bufandas ni barcos ni toros ni paraguas conseguirá por ellos si por ellos fuera la lluvia lo mojará no alcanzará perdón o gracia por ellos «con este poema no tomarás el poder» dice «con estos versos no harás la Revolución» dice «ni con miles de versos harás la Revolución» dice se sienta a la mesa y escribe (Gelman, 2012: 299-300) 
En este texto encontramos una reflexión sobre el papel de la literatura, específicamente de la poesía en un contexto político tan complejo como el de la dictadura argentina. Por una parte, Gelman asume explícitamente que el poema no va a cambiar la historia, hecho que representa un giro discursivo respecto a la poesía latinoamericana de la década de 1960, pues muchos de los textos escritos durante este periodo dan cuenta de la ferviente creencia en la posibilidad del cambio. Entonces, "Poema y testimonio se ven así unidos en una misma lucha contra dos rigideces la de la realidad espeluznante de la dictadura, y lo que se esperaría de un discurso político comprometido, al que acecha, sin embargo, la fijeza sentenciosa de lo catequístico, del previsible mensaje político" (Suárez, 2008: 70) .

En 1967, Mario Benedetti apuntaba: "un escritor latinoamericano de hoy, cualesquiera sean sus actitudes política o estética, y cualquiera sea el punto geográfico desde el cual opine, no puede (a menos que se pase de sutil o de embustero) inscribirse automáticamente en una objetividad sin fisuras" (1981: 39). De esta manera el escritor uruguayo explicitaba la necesidad de que los textos literarios fueran también textos de combate en un contexto que exigía del escritor una praxis artístico-política y una toma de partido clara.

En la década de los sesenta el discurso poético, en una corriente fortalecida a pesar del vituperio sistemático del nuevo establishment, encuentra nuevos temas, nuevas posibilidades, sobre todo nuevos motivos para reafirmar su convicción política y proyectar su compromiso ante el mundo en transformación que le rodea. La Revolución cubana, el asesinato de Luther King y del Che Guevara, la Unidad Popular Chilena [...] todo esto ronda el imaginario poético de aquellos autores decididos a seguir explorando el compromiso político en su obra (Aguilera, 2010: 60). 
Pasado el tiempo, dicha creencia se desvanece y esto se refleja también en la obra literaria. Gelman cree fervientemente en que la poesía tiene un valor que puede incidir en la realidad: "ni con miles de versos harás la Revolución' dice / se sienta a la mesa y escribe”. El lenguaje poético -desde su espacio, que es la creaciónforma parte activa de los distintos procesos históricos y políticos. La poesía resignifica, reescribe, evidencia y denuncia.

A mediados de 1975, frente a las amenazas de la Alianza Anticomunista, ${ }^{6}$ también conocida como la Triple A, Juan Gelman sale de Argentina para instalarse en Roma. Poco después de su partida se produce el golpe militar que desatará una cadena de hechos terribles en la vida del pueblo argentino y en su vida personal; acaso el evento más definitivo es el secuestro y asesinato de su hijo y su nuera embarazada de siete meses, además de la desaparición y muerte de amigos escritores como Paco Urondo, Haroldo Conti, Miguel Ángel Bustos, Rodolfo Walsh, entre otros. Frente a estos hechos funestos y dolorosos su quehacer literario más que nunca se verá atravesado por una serie de reflexiones políticas y sociales.

Hechos y relaciones (1980) es un libro que reúne poemas publicados anteriormente bajo el nombre de Relaciones y agrega una segunda parte bajo el título de Hechos, en la cual se compilan los poemas escritos entre 1974 a 1978. En ediciones posteriores de Hechos y Relaciones, se agregaron otros textos muy importantes de esta época, como el poema Carta abierta escrito en 1980 (del cual hablaremos más adelante). El volumen publicado en 1980 refleja una evidente fractura formal y lingüística con la que desarticulará el lenguaje poético para dar cuenta de su condición de exiliado.

${ }^{6}$ La Triple A fue un actor político colectivo con una organización interna (estructura, jerarquía, modus operandi) que ejerció una acción política no convencional, no legal y violenta, utilizando recursos del propio Estado (Rostica, 2011: 24). 
Este libro hace las veces de una reflexión por parte del sujeto lírico que se cuestiona su trabajo poético; el exilio será además de condición trágica, un tema nodal y permanente: "el exilio como otro mundo diario, como error. La persistencia en el error que puede originar una verdad" (Gelman, 2017: 64). Este tópico en la obra gelmaniana pasó de ser una mera cuestión de supervivencia a ser un problema ético e intelectual que desarrolló mediante un lenguaje que da cuenta del dolor, la separación y el trauma que genera la pérdida producto de la violencia de Estado. A partir del exilio, el escritor argentino consumará una obra en la que el sujeto lírico posee una conciencia política desde la cual enuncia un discurso desgarrado por el sufrimiento.

¿7 p.m. son?/¿̨subo la cuesta de setiembre/la cuesta de fantasmas?/¿en la esquina de vía portuense y costanera sur

un gorrión come migas de pan en las manos del moro?/:mateo pasa con una calandria cantando en la parte superior de su fe?/ ¿ una golondrinita atraviesa a la negra?/¿es golondrina que se llama sara y sale del nido que la negra tenía en el pelo y le daba vuelta alrededor cada vez que la negra salía a combatir?/ ¿con su campera llena de tiempo?I ¡su eternidad tomando el colectivo 60 para ir a combatir?/ ¿sus ojos con dos golondrinas detrás? ¿la una se murió una tarde a las 7 p.m. subiendo una cuesta del sur?/:la otra sacude su cabellera dulce en costanera sur y portuense/allí paco habla de la Revolución con jilgueritos (Gelman, 2012: 484).

El hablante poético devela el rostro verdadero de los lugares que han sido cercados por la violencia real (Buenos Aires) y sim- 
bólica (su exilio en Roma), además evidencia el dolor que le causa saberse lejos de su país. En "Pájaros", los sitios que habitó y habita se transforman en un espacio de doble faz que muestran y ocultan sus caras: “ ¿7 p.m. son?/ ¿subo la cuesta de setiembre/la/ cuesta de fantasmas?/¿en la esquina de vía portuense y costanera sur”. El primer sitio, Vía Portuense se ubica en Roma, el lugar donde Gelman vivió su exilio, por otra parte, Costanera Sur está en Buenos Aires, la ciudad del poeta. Ambos lugares conviven en el imaginario de la voz lírica, los cuales recorre como un fantasma que se pasea entre el pasado y el presente. La nostalgia por el país que ha dejado se evidencia una y otra vez. A lo largo del texto, el escritor argentino elude la literalidad y la referencialidad directa, para articular una serie de imágenes desde lo oblicuo y lo aparentemente sesgado, de tal forma que la lengua del exilio acomoda o desacomoda todas las vías de sentido en el discurso poético: "una cuesta del sur?/¡la otra sacude/ su cabellera dulce en costanera sur y portuense/allí/ paco habla de la Revolución con jilgueritos".

Hechos y relaciones configura una de las tantas memorias sobre la dictadura argentina. Encontramos en este libro dos estrategias que serán de uso común en la poesía latinoamericana reciente. Por una parte, la fractura del lenguaje $e^{7}$ como reflejo de la fisura con la realidad y, por otra, la representación de la violencia mediante una serie de alegorías que dan cuenta de lo sucedido en Argentina durante los primeros años del régimen. La escritura de Gelman es, en ese sentido, uno de los mejores ejemplos de la problematización de la forma en el texto poético, pues no estamos frente a un poema político tradicional, pero sí ante una política de la forma.

${ }^{7}$ La dictadura cívico militar en Argentina motivó a muchos escritores a acudir a lo que Orwell llama la neolengua, un discurso hecho a partir de neologismos y de una sintaxis fragmentada que da cuenta de la violencia producto de regímenes dictatoriales (Kertész, 2001: 92). 
El espacio del poemario registra también esta red de travesías en una sintaxis constantemente fracturada, suspendida, la puntuación sorprende y disloca el verso. La aparente dispersión semántica nombres, ciudades, tiempos diversos- se reúne en el tópico de la ausencia. Perdidas están las personas, los acontecimientos, los sueños. El poemario es el lugar de la ausencia (Guzmán, 2010: 44).

Por su parte, Carta abierta (1980) hace las veces de un un ejercicio de reflexión sobre la dictadura argentina, y más que ser una afirmación a través del discurso poético, este texto se erige como una duda permanente que apunta al trauma colectivo. En Carta abierta, Gelman trasciende el dolor personal para, mediante la representación literaria, hablar de las heridas de aquellos que fueron víctimas de la violencia y la vejación. Hay en este poema una descarnada conciencia del fracaso, una pérdida definitiva frente a un hecho histórico que marcó la vida de un país y de un continente. Marco Antonio Campos apunta:

Mientras el calendario de los años ochenta se rompe, Gelman sabe ya que las ilusiones del cambio y la esperanza de una sociedad justa y humana en la Argentina se han perdido. Es la hora de la derrota. Es la dolorosa conciencia de la derrota. Es la hora de irse con el corazón y los muertos a otra parte. Se perdieron las vidas de los compañeros, se marchitó la hierba del jardín del sueño y la utopía. Es hora de llevarse los sueños a otra parte. Ese país, Argentina, esa patria que está en la tierra, respira como puede (Gelman, 2013: 7).

El libro se conforma de veinticinco poemas dedicados a su hijo, Marcelo Ariel Gelman, quien fue asesinado durante la dictadura militar. El tema principal es el dolor individual y colectivo ante la pérdida, esto enunciado a través de un lenguaje que apela a las múltiples posibilidades semánticas de los vocablos. En el poema hay una constante interrogación retórica que cuestiona los vacíos sociales, históricos y lingüísticos. Al respecto, Daniel Freidemberg 
señala: "Carta abierta se constituye como una de las más arduas, hondas y lúcidas indagaciones en el dolor que presenta la poesía latinoamericana. También funge como un importante testimonio de la última dictadura en Argentina" (1998: 45).

Juan Gelman escribe una nota informativa que sirve de preámbulo al poema, en ella advierte al lector sobre una realidad que desafortunadamente no ha sido del todo esclarecida en los países víctimas de dictaduras. En escasas cinco líneas, el escritor argentino narra un doloroso episodio que concierne a su vida personal, cuenta al lector sobre el secuestro y pérdida de su hijo y su nuera a manos de un comando militar en Buenos Aires y, por si fuera poco, agrega que el hijo de ambos "nació y murió en el campo de concentración". Este breve párrafo es la antesala de un poema que hace las veces de homenaje a los "desaparecidos" y a "los ausentes para siempre”.

el 26 de agosto de 1976 mi hijo marcelo ariel y su mujer, claudia, encinta, fueron secuestrados en Buenos Aires por un comando militar. el hijo de ambos nació y murió en el campo de concentración. como en decenas de miles de otros casaos, la dictadura militar nunca reconoció oficialmente a estos "desaparecidos". hablo de "los ausentes para siempre". hasta que no vea sus cadáveres o a sus asesinos, nunca los daré por muertos (Gelman, 2018: 87).

En el libro, la paternidad se abre frente al dolor de la pérdida, y la voz lírica le habla al hijo desde un lenguaje dislocado: "hijo que vuela por quietudes/por", "hijito que el otoño desprendió”, "dando gritos de vos/hijo o temblor/", "hijo que hijé contra la lloradera/", "cielo que abrís hijando tu morida”, “qqué voy a hacer con mí/pedazo mío?/”, "deshijándote mucho/deshijándome/”, "¿niñito que pasás volando por”, "abierta al sol de la justicia?/_hijás?/”. Así pues, estamos frente una revisitación de la historia de su paternidad, des- 
de la infancia de su hijo hasta llegar a la recreación de su captura, tortura y asesinato. El sujeto poético oscila entre la esperanza y la desesperanza, porque a lo largo del texto se manifiesta la creencia en que el hijo está vivo, pero igualmente por momentos hay una completa derrota. "Los poemas se presentan como una larga queja, la de un padre huérfano de un hijo del cual no puede afirmar con toda seguridad que ha muerto" (Fabry, 2005: 66).

Uno de los temas principales que plantea la lectura de Carta abierta, versa sobre la naturaleza del lenguaje y sus límites, sobre todo pensado a la luz de un contexto de violencia: "el lenguaje opera al servicio del mecanismo de la imaginación que permiten decir aquello que no se es capaz de nombrar de otra manera, y lo hace mediante recursos de representación indirecta" (Deffis, 2010: 14-15). Por otra parte, la creación de neologismos o la desarticulación de la sintaxis tradicional ha producido una forma particular y novedosa de nombrar el dolor individual, colectivo y por ello histórico. Sostenemos que para una comprensión cabal de su obra no puede ser obviado el contexto social y político que da origen a sus temas y obsesiones. Es verdad que podemos ceñirnos a un análisis estrictamente estilístico o lingüístico, no obstante, nos interesa enfatizar que la estructura formal y semántica está en estrecha relación con la necesidad de nombrar un dolor existencial, una ruptura vital provocada por la violencia ejercida por la dictadura argentina. Al respecto, Aldo García apunta:

Cabe señalar que la mayoría de los trabajos acerca de la obra poética de Juan Gelman se inserta en marcos teóricos propios de la crítica e investigación literarias, por lo que la formación de palabras se ha relegado a un asunto meramente marginal, al privilegiar, por ejemplo, los fenómenos de intertextualidad con la poesía mística; la forma en que el dolor se manifiesta en sus poemas; así como la perspectiva, el sentimiento y las emociones que el poeta plantea 
con respecto del exilio, entre otras temáticas. Esta situación, a su vez, ha provocado que se ofrezcan descripciones imprecisas de las piezas léxicas revitalizadas o acuñadas por Juan Gelman, sobre todo, por no atender a su estructura formal y semántica, así como al contexto en que estas ocurren (García, 2013: 2017).

En ese sentido, las interrogantes que de este escenario surgen son múltiples, por ejemplo ¿hasta dónde el lenguaje poético puede nombrar el horror vivido en contextos de violencia política, en este caso una dictadura?, ¿cuáles son las estrategias literarias que sigue un escritor para dar cuenta de la violencia? Estas preguntas cuestionan la función de la poesía en escenarios de profundo dolor.

¿me vas a disculpar que te hije mucho?/ ¿dónde estás mesmo ahorita?/¿descansás?/ ¿nadie tortura tu blancor?/¿ya mudo quietás tu luz contra tinieblas?/¿̨late tu oscuridad?/¿llagás en puro fuego capaz de vos?/¿la muerte sostenés con tus manitas para que no aplaste lo que sube de vos?/ ¿amor que dieras al puro ajeno como revolar contra el contrario de la ser dolida?/ ¿contra el hambre que golpia tu golpear?/ ¿contra la sed que moja tus pedazos?/ ¡cómo beber que seca?/sol/¿bueyás?/ (Gelman, 2013: 373).

Gelman apela, entre otros recursos, a la radicalización del lenguaje mediante neologismos y una clara ruptura de la sintaxis para enunciar la pérdida y la ausencia de su hijo que es también la representación simbólica de los desaparecidos durante la dictadura militar en Argentina. La poesía gelmaniana reactiva la memoria, 
"el vestigio del ser representado en el poema, los rostros ausentes que están presentes como reminiscencia del pasado" (Villegas, 2007: 7).

\section{Reflexiones a manera de conclusión}

La escritura poética posee un lenguaje específico -no exclusivo, en la medida que no tiene por qué limitarse a temáticas o formas establecidas- de ello da muestra la obra gelmaniana. Su escritura problematiza el concepto de poesía política, pues de una u otra manera cuestiona y subvierte la forma literaria de este género. Recordemos que, para los escritores de las décadas de los setentas y posteriores, la noción de "compromiso político" no será en modo alguno la misma que en los años de 1960. Este cambio de paradigma nos parece fundamental y definitorio para entender el devenir de la poesía que se ocupa de temas políticos a finales del siglo xx y lo que va del xxi, pues nos lleva a pensar que estamos frente a una nueva realidad que obliga al escritor a repensar su ejercicio poético. Para llevar a cabo tal empresa se deben tomar en cuenta dos aspectos: el primero, un cambio en la forma de concebir la historia y, segundo, nuevas estrategias discursivas.

La obra de Juan Gelman es sin duda un parteaguas para la poesía latinoamericana, pues -como en este trabajo quedó evidenciadosu escritura refleja una ruptura en todos los órdenes, esto como producto de la violencia dictatorial en Argentina. Su conciencia de la praxis política y de una serie de sucesos desafortunados y terribles en la vida del colectivo y en su vida personal, definirán su quehacer poético. La invención de una neolengua poética que busca desesperadamente encontrar respuestas en una historia signada por la represión es acaso una de las aportaciones más importantes para la poesía latinoamericana, pues implícita a esta invención o experimentación está una profunda reflexión sobre el papel del escritor 
frente a eventos políticos tan avasalladores; en su caso, sobre la dictadura argentina.

\section{Bibliografía}

Aguilera López, Jorge, 2010, Más allá de la marginación existe la estética: El compromiso político en la poesía mexicana. Un estudio de Enriquez González Rojo, Tesis de Maestría, Universidad Nacional Autónoma de México, México.

Alemany Bay, Carmen, 1997, Poética coloquial hispanoamericana, Universidad de Alicante, España.

Benedetti, Mario, 1981, "Situación del escritor en América Latina”, en El ejercicio del criterio, Nueva Imagen, México.

Cardenal, Ernesto, 1975, "Prólogo", en Poesía Nicaragüense, Ediciones el pez y la serpiente, Nicaragua.

Deffis, Emilia, 2010, Figuraciones de lo ominoso. Memoria histórica y novela posdictatorial, Editorial Biblos, Argentina.

Fabry, Geneviève, 2005, "La escritura del duelo en la poesía de Juan Gelman", Anuario de Estudios Filológicos, vol. XXVIII, Université Catholique de Louvain, pp. 55-69.

Ferreira Navarro, Marcos, 2014, "Operación Cóndor: antecedentes, formación y acciones", Revista Ab Intio, núm. 9, pp. 1-27.

Freidemberg, Daniel, 1999, Juan Gelman en el concierto de la literatura latinoamericana de denuncia, Ediciones Altamar, Argentina.

García Ávila, Aldo, 2013, “'Donde tu hermosura se ensombra’: problemas morfosemánticos en el 'Comentario VII', de Juan Gelman”, Acta Poética, vol. 34, núm. 2, diciembre, pp. 213236.

Gelman, Juan, 2012, Poesía Reunida, Seix Barral, España. 
,2013, "Selección y notas introductorias de Marco Antonio Campos", en Material de Lectura. Disponible en: http://www. materialdelectura.unam.mx/index.php/poesia-moderna/16poesia-moderna-cat/333-183-juan-gelman?showall=1 , 2018, Otro mundo. Antología (1956-2007), Fondo de Cultura Económica, México.

Guzmán, Raquel, 2010, “La ciudad, la poesía, Juan Gelman”, Tópicos del Seminario, núm. 24, julio-diciembre, pp. 41-53.

Kertész, Imre, 2001, La lengua exiliada, Adan Kovacsics (trad.), Taurus, Colombia.

Luján Atienza, Ángel Luis, 2005, Pragmática del discurso lírico, Arco / Libros, Madrid.

Padilla, Heberto, 1982, Fuera del juego, Círculo de Poesía, La Habana.

Rostica, Julieta, 2011, "Apuntes 'Triple A' Argentina 1973-1976”, Desafíos, vol. II, núm. 23, pp. 21-51.

Sarlo, Beatriz, 1994, Escenas de la vida posmoderna. Intelectuales, arte y videocultura en la Argentina, Ariel, Buenos Aires.

Suárez, Modesta, 2008, "Un pedacito de la belleza que vendrá. Poesía y testimonio en la poesía de Juan Gelman", Revista del CESLA, núm. 11, pp. 69-78.

Villegas, Aguilar, 2007, Poesía y memoria, Universidad Iberoamericana, México. 